\title{
O PROBLEMA DO RELATIVISMO EM \\ HEIDEGGER E GADAMER
}

\author{
Rui Sampaio da Silva \\ Universidade dos Açores
}

O problema do relativismo é um dos principais problemas que se coloca ao nível da interpretação do pensamento de Heidegger e de Gadamer. Apesar de os referidos filósofos não se considerarem relativistas, a verdade é que os seus críticos têm alertado, não poucas vezes, para as consequências relativistas da fenomenologia hermenêutica. A correcta apreciação desta questão é dificultada pelo facto de não haver um consenso claro sobre o sentido do termo "relativismo", o qual é usado em diferentes acepções por diferentes autores. No que se segue, procurar-se-á, em primeiro lugar, clarificar o conceito de relativismo para posteriormente avaliar em que medida o pensamento de Heidegger e de Gadamer é vulnerável à acusação de relativismo.

\section{O conceito de relativismo}

Uma das dificuldades que se coloca quando se pretende definir o conceito de relativismo prende-se com o facto de ele ser aplicável a vários domínios. Deste modo, surgem diferentes variedades de relativismo, como o relativismo cognitivo, moral, cultural, ontológico ou semântico. Note-se, a este respeito, que é possível adoptar uma destas formas de relativismo e rejeitar outras; por exemplo, há quem adopte o relativismo moral ao mesmo tempo que rejeita o relativismo cognitivo.

Se procurarmos investigar o que há de comum a todas estas variedades do relativismo, podemos ser confrontados com diferentes respostas. Alguns autores entendem que a característica mais importante do relativismo consiste na ideia de que o conhecimento, as normas morais ou os significados, por exemplo, dependem de um determinado contexto, que tanto pode ser uma 
sociedade, uma cultura, uma época, o paradigma de uma comunidade de investigação ou um esquema conceptual. Como ilustração desta tendência, podem ser mencionadas as seguintes definições de relativismo epistemológico:

O relativismo epistemológico é a ideia de que o conhecimento (e/ou a verdade) é relativo - ao tempo, ao lugar, à sociedade, à cultura, à época histórica, ao esquema ou enquadramento conceptual, ou à educação ou convicção pessoal. ${ }^{1}$ O relativismo é a ideia de que a verdade e o conhecimento não são absolutos ou invariáveis, mas dependem do ponto de vista, das circunstâncias ou das condições históricas. ${ }^{2}$

De acordo com tais definições, a fenomenologia hermenêutica de Heidegger e de Gadamer corre o sério risco de ser declarada como relativista, porque ela chama, efectivamente, a atenção para o modo como o conhecimento e a interpretação dependem de um contexto ou de um horizonte de compreensão. Todavia, as definições acima citadas não mencionam explicitamente uma tese que normalmente se associa ao relativismo, a saber, a tese de que as diferentes perspectivas em conflito num determinado domínio são igualmente legítimas. Rorty, na sua definição do relativismo, enfatiza precisamente este ponto: “O 'relativismo' é a tese de que toda a crença sobre um certo tópico, ou talvez sobre qualquer tópico, é tão boa como outra qualquer."” Mas ele acrescenta de imediato que ninguém defende esta tese; os assim chamados relativistas seriam, simplesmente, pessoas que rejeitam uma concepção algorítmica da racionalidade. De facto, o relativista radical é, em rigor, uma ficção intelectual e, tal como se argumenta desde a crítica que Platão dirige ao relativismo de Protágoras no Teeteto, uma figura incoerente. Com efeito, a tese relativista segundo a qual a verdade varia conforme as diferentes perspectivas tem, para o relativista, a desagradável consequência de que é verdadeiro o juízo daqueles que consideram o relativismo uma doutrina falsa... Em todo o caso, mesmo que não consigamos encontrar um relativista radical, i.e., alguém que entenda que "todas as crenças sobre um certo tópico são igualmente boas", podemos, todavia, encontrar relativistas moderados, ou seja, pessoas que, ao reconhecerem a dependência do conhecimento e da moralidade, por exemplo, perante o contexto social, histórico e cultural, concluam que há, em diversos domínios, perspectivas mutuamente incompativeis que devem ser aceites como igualmente legítimas. Por outras palavras, pode ser considerado como relativista não apenas aquele que aceita todas as crenças ou perspectivas sobre um determinado assunto, mas também aquele que, tendo

Harvey Siegel, "Relativism", in J. Dancy e E. Sosa (eds.), A Companion to Epistemology, Oxford, Blackwell, 1996, pp. 428-9.

2 A. Grayling, "Wittgenstein on Scepticism and Certainty", in H.-J. Glock (ed.), Wittgenstein: A Critical Reader, Oxford, Blackwell, 2001, p. 308.

3 Richard Rorty, Consequences of Pragmatism, Minneapolis, University of Minnesota Press, 1982, p. 166. 
excluído algumas crenças por serem manifestamente absurdas ou aberrantes, tende a aceitar de forma indiferente e acrítica as demais perspectivas em conflito.

Assim sendo, podemos apresentar o relativismo como a conjunção de duas teses:

(a) a tese contextualista: algo (como o conhecimento, os significados, as normas morais ou as práticas culturais) depende de um determinado contexto social, histórico e cultural ou de um esquema conceptual;

(b) a tese indiferentista ou igualitária: as diferentes perspectivas em conflito num determinado domínio são igualmente legítimas.

Enquanto a figura inverosímil do relativista radical defende rigidamente a segunda tese, o relativista moderado poderá ser mais flexível e rejeitar, como já se disse, aquelas crenças ou perspectivas totalmente indefensáveis. No que se segue, considerar-se-á o relativismo como a conjunção da tese contextualista e da tese indiferentista ou igualitária e defender-se-á que a hermenêutica não deve ser entendida como um relativismo, mas sim como um contextualismo. Ela reconhece, de facto, a importância epistemológica do contexto, mas não nos conduz a uma aceitação indiferente das interpretações ou perspectivas em conflito.

\section{O problema do relativismo em Heidegger}

Podemos reflectir sobre o problema do relativismo em Heidegger tomando como fio condutor a sua análise da compreensão e do conceito de verdade em Ser e Tempo. Nesta obra, a compreensão é apresentada não como um comportamento ocasional nem como um modo particular de conhecimento (contraposto à explicação), mas como o próprio modo de ser do Dasein; mais precisamente, a compreensão é uma apreensão e projecção de possibilidades de ser ou de agir no âmbito de um determinado contexto prático, social ou histórico. A interpretação, por seu turno, é concebida por Heidegger como a elaboração das possibilidades projectadas na compreensão. Um aspecto de decisiva importância na reflexão hermenêutica presente em Ser e Tempo é a análise da estrutura de antecipação (Vor-Struktur) da compreensão. De acordo com Heidegger, a compreensão é inevitavelmente condicionada.pelo horizonte de possibilidades dentro do qual crescemos e a partir do qual interpretamos os entes ou a nossa experiência do mundo. Assim sendo, Heidegger defende que não pode haver interpretação sem pressupostos, porque ela pressupõe inevitavelmente um determinado contexto prático (uma posse prévia; Vorgriff), uma 
determinada perspectiva (uma visão prévia; Vorsicht) e, inclusivamente, uma grelha conceptual (uma concepção prévia; Vorgriff).

Esta estrutura de antecipação da compreensão não tem, porém, como consequência o relativismo. Em vez de adoptar uma atitude de aceitação indiferente das diferentes interpretações que se nos apresentam, Heidegger alerta, pelo contrário, para o facto de existirem interpretações inadequadas que impõem conceitos estranhos àquilo que se interpreta: "A interpretação pode extrair a conceptualidade relativa ao ente que se tem de interpretar do próprio ente ou submeter o ente a conceitos aos quais ele se opõe na sua maneira de ser."4 De forma análoga, Heidegger defende que a interpretação não deve ser guiada por "opiniões ocasionais (Einfälle) e conceitos populares", devendo, antes, desenvolver-se "a partir das próprias coisas". 5 Estas passagens comprovam que Heidegger se opõe a uma atitude relativista. Todavia, a sua distinção entre interpretações adequadas e inadequadas é muito vaga. Será necessário esperar por Gadamer para encontrar um tratamento satisfatório da referida distinção.

No âmbito da sua análise do conceito de verdade, Heidegger afirma que "toda a verdade [...] é relativa ao ser do Dasein" e que "só há verdade na medida em que e enquanto o Dasein é."6 As leis de Newton, por exemplo, antes de serem descobertas não eram verdadeiras (nem falsas). Ora, para se compreender devidamente estas afirmações, é necessário ter presente que Heidegger, influenciado pelos gregos, concebe a verdade como a não-ocultação (Unverborgenheit) dos entes, razão pela qual ele considera que a verdade proposicional se funda na descoberta dos entes. Tal descoberta, por sua vez, só é possível no âmbito de um horizonte de inteligibilidade ou de um espaço de manifestação dos entes, que Heidegger designa, de forma idiossincrática, como "abertura" ou "estado-de-aberto" (Erschlossenheit). A abertura, no sentido heideggeriano da expressão, é o nível fundamental da verdade e envolve uma dimensão pragmática (uma rede de práticas sociais), uma dimensão afectiva e ainda uma dimensão quase-transcendental, constituída pela estrutura da temporalidade. Quando Heidegger afirma, por conseguinte, que a verdade é relativa ao ser do Dasein, ele não está a defender um relativismo subjectivista, mas apenas a reflectir o facto de a revelação dos entes remeter para a actividade descobridora do Dasein. Pode considerar-se que a verdade é relativa a um determinado horizonte de compreensão, dado que, por um lado, a manifestação dos entes ocorre num determinado contexto histórico ou social e, por outro, se tem acesso a diferentes aspectos da realidade a partir de diferentes horizontes: "Porque o Dasein é, de acordo com a sua própria existência, histórico, as possibilidades de acesso e os modos de interpretação dos entes são,

Martin Heidegger, Sein und Zeit, Tübingen, Max Niemeyer Verlag, 1993, p. 150.

5 Ibid., p. 153.

6 Ibid., p. 226. 
eles próprios, diferentes e variáveis em diferentes situações históricas."7 Assim sendo, em vez de um relativismo, o que Heidegger nos oferece é algo de mais inofensivo: um "realismo plural", nas palavras de Hubert Dreyfus. A noção de realismo plural significa que não há uma concepção privilegiada da realidade, porque diferentes interpretações da realidade podem ser conduzidas por diferentes questões e ter o mérito de iluminar diferentes aspectos da realidade. ${ }^{8}$ Tal como diz Dreyfus: "A realidade pode ser revelada de muitas maneiras e nenhuma é metafisicamente básica." " Consideremos, a este respeito, a seguinte afirmação de Heidegger:

Assim, também não se pode dizer que a doutrina de Galileu da queda livre dos corpos é verdadeira, e que a de Aristóteles, que ensina que os corpos leves tendem para cima, é falsa; pois a concepção grega da essência do corpo, do sítio e da relação de ambos assenta numa outra interpretação do ente [...]. Ninguém afirmaria que a poesia de Shakespeare é mais evoluída que a de Ésquilo. Mas ainda mais impossível é dizer que a apreensão moderna do ente é mais correcta que a grega. ${ }^{10}$

Retirada do seu contexto, esta passagem parece ser uma declaração de relativismo, mas é necessário relembrar que Heidegger rejeita claramente a ideia de que todas as interpretações da realidade são igualmente legítimas. Note-se que o realismo plural é, apesar de plural, um realismo, porque admite a existência de interpretações que deturpam a realidade. Quando Heidegger, por conseguinte, insinua que a ciência aristotélica e a galilaica são igualmente verdadeiras, ele parece partir simplesmente do princípio de que Aristóteles e Galileu formularam diferentes questões e foram guiados por diferentes interesses. Na medida em que a física aristotélica e a galilaica oferecem respostas para diferentes questões, a afirmação de que são ambas verdadeiras pode ser reformulada como a afirmação de que as respectivas interpretações da natureza conseguem captar diferentes aspectos da realidade. Em todo o caso, nada impede Heidegger de afirmar que, em muitos domínios, a física galilaica é preferível à física aristotélica.

Uma outra forma de ilustrar o distanciamento de Heidegger perante o relativismo passa pela distinção entre autenticidade e inautenticidade. A "abertura" (Erschlossenheit) ou o "ai" (Da) do Dasein, em que os entes se

7 Martin Heidegger, Grundprobleme der Phänomenologie, Frankfurt/M, Vittorio Klostermann, 1989, p. 30.

8 Cf. Hubert Dreyfus, Being-in-the World, Cambridge, MA, The MIT Press, 1995, pp. 261-65 e 277-81.

9 Ibid., p. 280.

${ }^{10}$ Martin Heidegger, Holzwege, Frankfurt/M, Vittorio Klostermann, 1977, p. 77; Caminhos de Floresta, Lisboa, Fundação Calouste Gulbenkian, 2002, p. 99. Seguimos, nesta citação, a tradução portuguesa de Alexandre Franco de Sá. 
manifestam, pode ser avaliada diferentemente, dado que existe uma diferença fundamental, segundo Heidegger, entre formas autênticas e inautênticas de estar no mundo e de nos abrirmos aos entes. Note-se que esta diferença não é apenas individual; certas épocas podem favorecer a autenticidade ou a inautenticidade. Assim sendo, também no plano das interpretações culturais Heidegger se demarca de um relativismo segundo o qual todas as perspectivas teriam o mesmo valor. $\mathrm{O}$ recurso ao ideal de autenticidade como antídoto contra o relativismo enferma, porém, de um problema, a saber, o carácter ${ }^{*} v a g o$ da noção de autenticidade. Segundo Heidegger, a autenticidade consiste, por um lado, num esforço de distanciamento perante o discurso impessoal quotidiano e pela tentativa de projectar a nossa existência a partir de nós próprios e, por outro, numa aceitação do nosso ser-para-a-morte. Este ideal, todavia, permanece impreciso, o que levou Tugendhat e Habermas a acusarem Heidegger de ter advogado um "decisionismo" vazio.

\section{O problema do relativismo em Gadamer}

Em Gadamer, a análise heideggeriana da estrutura de antecipação da compreensão sobrevive na forma de uma reabilitação do preconceito (Vorurteil). Não há, segundo Gadamer, uma compreensão livre de preconceitos, razão pela qual a interpretação é um processo interminável de elaboração das nossas projecções de sentido. Note-se que Gadamer não se limita a enunciar a tese relativamente pálida de que não nos conseguimos libertar da acção dos preconceitos. Ele vai mais longe e concebe os preconceitos como fontes de inteligibilidade e condições da experiência do mundo. Contra uma hermenêutica da reconstrução, orientada para a reconstituição dos pensamentos ou vivências de um autor, Gadamer propõe, por conseguinte, uma hermenêutica da integração, de acordo com a qual a compreensão envolve, por parte do intérprete, uma apropriação pessoal daquilo que é dito. Tal como para Heidegger, a interpretação, segundo Gadamer, não é subjectiva nem objectiva, mas sim projectiva.

Para analisar a nossa pré-compreensão do mundo, Gadamer, inspirando-se em Nietzsche e Husserl, recorre à noção de horizonte. Numa perspectiva hermenêutica, o horizonte pode ser caracterizado como o conjunto particular de conceitos, crenças e valores com base nos quais compreendemos o mundo e os outros. Uma vez que não é possível abstrairmo-nos do nosso horizonte pessoal, a compreensão é, consequentemente, concebida como uma fusão de horizontes. Isto significa que a compreensão tem um carácter produtivo e não meramente reprodutivo:

O sentido de um texto ultrapassa o seu autor não apenas ocasionalmente, mas sempre. Por isso, a compreensão não é apenas um comportamento reprodutivo, 
mas sempre, também, um comportamento produtivo. Compreende-se de modo diferente, quando se compreende efectivamente. ${ }^{11}$

A última frase pode, mais uma vez, levantar a suspeita de relativismo, mas a hermenêutica de Gadamer é, na realidade, uma tentativa engenhosa de navegar entre Cila e Caríbdis, entre o relativismo e o objectivismo hermenêutico, entre a proliferação descontrolada de interpretações e a crença dogmática na existência de uma única interpretação correcta do interpretandum.

Para se compreender devidamente a estratégia de Gadamer, é fundamental ter presente a sua tese de que o sentido e a identidade de um texto ou de uma obra de arte são indissociáveis do contexto interpretativo ou do nosso horizonte de compreensão. A reflexão gadameriana sobre a arte, que serve de modelo à sua reflexão sobre as ciências humanas, é a este respeito esclarecedora.

Em Verdade e Método, pode ler-se que a obra de arte não existe em si, abstraída da sua relação com o intérprete ou espectador, o que é particularmente claro no caso das artes reprodutivas, como a música e o teatro. Uma partitura musical não é ainda música, pois só se torna música graças à interpretação musical, a qual pode assumir inúmeras formas. No domínio do teatro, encontra-se uma situação análoga, e por isso Gadamer chega a afirmar que "o espectador de hoje não vê apenas de modo diferente, ele vê também algo de diferente."12 A interpretação da obra de arte não é algo que lhe seja extrínseco, mas um acontecimento de sentido que afecta quer a obra quer o intérprete. $\mathrm{E}$ estas considerações, como se disse, não se circunscrevem à música ou ao teatro, uma vez que a interpretação pertence ao ser da própria obra de arte em geral. ${ }^{13}$ Deste modo, Gadamer afirma que "a leitura pertence de forma essencial à obra de arte literária" 14 e estabelece um paralelismo entre a interpretação musical e a interpretação dos textos quando pergunta: "Não pertence a compreensão ao acontecimento de sentido de um texto, tal como o trazer-à-audição pertence à música?"15 $\mathrm{Na}$ página seguinte, ele responde a esta questão: "A compreensão deve ser pensada como uma parte do acontecimento do sentido, no qual o sentido de todos os enunciados - os da arte e os de toda a restante tradição - se forma e se completa.” Tendo em conta esta relação íntima entre compreensão e sentido, bem como a concepção da compreensão como uma fusão de horizontes, Gadamer critica a noção de um "sentido em si". ${ }^{16}$ Ora,

11 Hans-Georg Gảdamer, Wahrheit und Methode (Gesammelte Werke, Bd.1), Tübingen, J. C. B. Mohr, 1999, pp. 301-2.

12 Ibid., p. 153.

13 Segundo Gadamer, a obra de arte deve ser compreendida como jogo, e como tal envolve uma referência essencial ao intérprete ou espectador.

14 Gadamer, Wahrheit und Methode, p. 166.

15 Ibid., p. 169.

16 Cf. ibid., p. 477. 
sem esta noção, torna-se ilusório acreditar que só existe uma interpretação correcta de uma obra ou texto.

Mas não é apenas o sentido que depende do contexto; o mesmo se passa com a própria identidade do objecto da interpretação. É conveniente ter presente, a este propósito, a importância da ideia de relação na ontologia de Gadamer; as coisas são o que são em função do respectivo contexto e das suas relações com outras coisas. Assim, o objecto da interpretação não é independente da compreensão, daí resultando que a compreensão, além de ser um acontecimento de sentido, também tem um alcance ontológico, visto que o acontecimento da compreensão afecta a própria realidade. Esta tese de Gadamer funda-se, em última instância, na sua concepção da linguagem como meio universal da experiência do mundo ou na ideia de que "o mundo só é mundo na medida em que vem à linguagem". ${ }^{17}$ Desta concepção da linguagem resulta não apenas que a compreensão tem um carácter linguístico, mas também que os objectos não são independentes da sua articulação linguística. Da mesma forma que critica a ideia de um "sentido em si", Gadamer também critica explicitamente a ideia de um "objecto em si", ${ }^{18}$ as coisas são o que são na medida em que são trazidas à linguagem. No caso específico dos textos, isto significa que a identidade de um texto tem um carácter relacional e não pode ser apreendida independentemente dos diferentes contextos a partir dos quais é interpretada. Deste modo, um texto admite múltiplas interpretações que não se excluem mutuamente, pois são apreensões de diferentes aspectos de um mesmo texto. De forma análoga, a realidade tem muitas faces, e o pluralismo hermenêutico reflecte precisamente a diversidade de formas através das quais a realidade se manifesta.

Todavia, Gadamer não se pode limitar a defender, contra o dogmatismo ou o objectivismo hermenêutico, que existem sempre várias interpretações correctas de um texto; ele deve também insistir, contra o relativismo ou anarquismo hermenêutico, que existem interpretações incorrectas de um texto. Para exorcizar o espectro do relativismo que paira pontualmente sobre a sua obra, Gadamer, no decurso da sua reflexão hermenêutica, dedica especial atenção àqueles aspectos do fenómeno da compreensão que limitam a arbitrariedade interpretativa Assim, e em primeiro lugar, ele tem o cuidado de mostrar como a coerência pode constituir um critério para distinguir entre interpretações adequadas e inadequadas; em princípio, as antecipações inadequadas de sentido que nós projectamos sobre um texto não conseguem gerar uma leitura coerente do mesmo:

Assim o movimento da compreensão corre permanentemente do todo para a parte e da parte para o todo. A tarefa é alargar a unidade do sentido compreendido em círculos concêntricos. A concordância [Einstimmung] de todos os por- 
menores com o todo é o respectivo critério da correcção da compreensão. A ausência de tal concordância significa o fracasso da compreensão. ${ }^{19}$

Em segundo lugar, a pertença do intérprete e do interpretandum a uma tradição comum limita, em princípio, a arbitrariedade dos pressupostos à luz dos quais o intérprete compreende um texto, por exemplo. Com efeito, a tradição em que nascemos e ao abrigo da qual somos educados é, em grande parte, constitutiva de nós próprios, e tal facto milita contra um anarquismo hermenêutico:

Assim, a crença ingénua na objectividade do método histórico era uma tal ilusão. Mas o que surge no seu lugar não é um relativismo débil. Não é aleatório nem arbitrário aquilo que nós próprios somos e aquilo que somos capazes de ouvir do passado. ${ }^{20}$

Em terceiro lugar, o papel decisivo que a verdade desempenha no processo de compreensão também comprova o distanciamento de Gadamer perante o relativismo. Com efeito, na perspectiva de Gadamer, a compreensão é dominada pelo princípio da "antecipação da perfeição", o qual envolve uma pressuposição da verdade e da coerência do interpretandum. A compreensão, que não pode ser uma mera reconstituição das vivências ou pensamentos de outrem, revela-se como um processo de entendimento orientado para a busca da verdade, e tal busca impele-nos a ir para além do nosso horizonte de compreensão, dando origem a um processo de fusão de horizontes. Também por esta via é clara a oposição de Gadamer ao relativismo.

De um ponto de vista epistemológico, o modelo da fusão de horizontes assume uma importância decisiva, pois é ele que permite imunizar o contextualismo hermenêutico contra o relativismo. Com efeito, a ideia segundo a qual as diferentes perspectivas em conflito num determinado domínio devem ser aceites por serem incomensuráveis entre si é posta em causa pelo referido modelo. Contra a pressuposição da existência de perspectivas rigidamente incomensuráveis, 'o processo de fusão de horizontes mostra que não há, em princípio, dificuldades absolutamente intransponíveis de comunicação e de compreensão. Aquilo que inicialmente nos parece estranho ou ininteligível pode, através do esforço interpretativo, tornar-se inteligível e susceptível de discussão racional. Em clara oposição à noção relativista de incomensurabilidade, Gadamer tem o cuidado de salientar que um "horizonte fechado" é uma abstracção, ${ }^{21}$ dado que o nosso horizonte se transforma no decorrer das nossas experiências e, em particular, mediante o contacto com outros universos cultu-

${ }^{20}$ Hans-Georg Gadamer, Wahrheit und Methode - Ergänzungen (Gesammelte Werke, Bd. 2), Tübingen, J. C. B. Mohr, 1999, p. 40.

${ }^{21}$ Cf. Gadamer, Wahrheit und Methode, p. 309. 
rais. Um horizonte de compreensão tem um carácter não apenas finito, mas também aberto. Deste modo, a diversidade de horizontes de compreensão não significa que não haja padrões de racionalidade partilhados por diferentes comunidades ou culturas; pelo contrário, a experiência da comunicação humana aponta para a existência de tais padrões. Note-se, a este propósito, que a crítica gadameriana de uma razão absoluta tem apenas como objectivo alertar para o carácter histórico e situado da razão, sem pôr em causa o "ideal da razão", ou seja, "o ideal de um mundo inteligível, ordenado racionalmente". ${ }^{22}$ Tal como Gadamer afirma, por detrás da relatividade de linguagens e convenções está algo de comum: a razão humana. ${ }^{23}$

É também o modelo da fusão de horizontes que permite a Gadamer defender-se da acusação de relativismo linguístico. Esta acusação tem origem no facto de Gadamer conceber a linguagem como o meio universal da experiência humana e de considerar que diferentes tradições culturais e linguísticas contêm diferentes visões do mundo. Todavia, o "mundo linguístico" em que cada um de nós vive não impede o acesso a outros horizontes culturais; cada língua, longe de ser uma prisão, tem a capacidade de se abrir às outras. ${ }^{24}$ As diferentes visões linguísticas do mundo não constituem, como Gadamer tem o cuidado de frisar, "uma relativização do mundo" nem são meras aproximações a um "mundo em si". Pelo contrário, a noção de um "mundo em si" é, segundo Gadamer, problemática e não pode significar senão a totalidade das diferentes visões do mundo ou perspectivas sob as quais o mundo se oferece. ${ }^{25}$ Gadamer estabelece, neste contexto, uma analogia com a análise husserliana da percepção, de acordo com a qual os objectos se manifestam sob diferentes aspectos ou perspectivas (Abschattungen), consistindo a "coisa em si" na continuidade das referidas perspectivas. De forma análoga, não existe, segundo Gadamer, um "mundo em si" contraposto às diferentes visões linguísticas do mundo; "aquilo que o próprio mundo é não é diferente das visões por meio das quais ele se apresenta." ${ }^{26}$ Refira-se, porém, que no caso das visões linguísticas do mundo, "cada uma delas contém em si potencialmente todas as outras, i.e., cada uma pode alargar-se em direcção às outras."27

O modelo da fusão de horizontes conduz-nos, assim, para além do objectivismo e do relativismo. Conduz-nos para além do objectivismo, porque chama a atenção para o facto de a inteligibilidade de textos, obras de arte ou acções depender de um determinado contexto ou horizonte de compreensão.

${ }^{22}$ Hans-Georg Gadamer, Hermeneutik im Rückblick (Gesammelte Werke, Bd. 10), Tübingen, J. C. B. Mohr, 1999, p. 246.

${ }^{23}$ Cf. Gadamer, Wahrheit und Methode - Ergänzungen, p. 204.

${ }^{24}$ Cf. Gadamer, Wahrheit und Methode, p. 452.

${ }^{25}$ Cf. $i b i d .$, pp. 451-2.

${ }^{26}$ Ibid., p. 451.

27 Ibid., p. 452. 
Por outro lado, o referido modelo evita o relativismo ao defender a possibilidade da comunicação e da discussão racional entre os diferentes horizontes.

\section{Conclusão: contextualismo e relativismo}

Já por várias vezes se utilizou, neste texto, o termo "contextualismo". Convém, portanto, esclarecê-lo. O contextualismo, tomado como uma teoria da justificação epistémica, assemelha-se ao fundacionalismo na medida em que admite a existência de crenças básicas ou fundamentais, mas dele difere sob dois aspectos determinantes: em primeiro lugar, o contextualismo nega que haja crenças intrinsecamente credíveis, explicando o estatuto privilegiado das crenças básicas a partir de factores sociais e pragmáticos; em segundo lugar, o contextualismo entende que as crenças básicas variam em função dos diferentes contextos de investigação e de acção.

A hermenêutica de Heidegger e de Gadamer é um contextualismo, porque defende que o sentido, a compreensão, a interpretação e a justificação epistémica dependem do contexto, i.e., de uma situação histórica ou de um horizonte de compreensão. Também ao nível da noção de verdade, a relação com o contexto é fundamental. À semelhança de Heidegger, Gadamer sublinha este ponto: "O estar-condicionado [Bedingtheit] não é, portanto, um dano do conhecimento histórico, mas um momento da própria verdade." 28

Em todo o caso, o contextualismo hermenêutico não é um relativismo, pois o hermeneuta ou o contextualista não são obrigados a considerar todos os contextos como igualmente apropriados, podendo, pelo contrário, criticar certas interpretações ou perspectivas sobre o mundo. Reconhecer a diversidade de horizontes de compreensão e a impossibilidade de suspender a nossa pertença a uma determinada tradição cultural não nos impede de avaliar racionalmente, no âmbito de uma busca dialógica e cooperativa da verdade, as diferentes perspectivas em conflito num determinado domínio. Segundo o relativismo cultural, não podemos julgar culturas significativamente diferentes da nossa, mas apenas aceitá-las como são. Ora, o contextualista não está condenado a esta aceitação indiferente ou acrítica das diferentes tradições culturais; Wittgenstein, por exemplo, que é um ilustre representante do contextualismo, afirmou em Da Certeza que combateria uma cultura em que se consultasse um oráculo em vez de um físico...

O contextualismo reconhece que o facto de o contexto condicionar as nossas perspectivas morais ou cognitivas gera uma pluralidade de perspectivas. Algumas destas perspectivas podem ser consideradas como complementares ou como explorações de diferentes faces de uma obra ou da própria realidade. Outras perspectivas, pelo contrário, podem negar-se mutuamente, e é a 
este nível que melhor se compreende a diferença entre o contextualista e o relativista; enquanto este último tende a atribuir legitimidade às diferentes perspectivas em conflito, um contextualista como Gadamer acredita que aquilo que há de comum entre os diversos horizontes de compreensão pode servir de base para um diálogo produtivo orientado para o entendimento intersubjectivo e para a correcção indefinida dos nossos preconceitos.

Em suma, com esta distinção entre contextualismo e relativismo podemos absolver a fenomenologia hermenêutica de Heidegger e de Gadamer da acusação de relativismo. 